\title{
Ion Beam Induced Doping in Synthetic Elastomer
}

\author{
S. Najidha and P. Predeep
}

\begin{abstract}
Development of high electric conductivity in polymers by doping triggered the emergence of polymers in electronics and optoelectronics. Semiconducting properties are established in conjugated polymers by a process similar doping in inorganic semiconductors. We had demonstrated that as in the case of chemical doping, ion implantation also could be used effectively in doping elastomers. Implant doping can create an insulator-semiconductor transition in Natural Rubber (cis 1, 4 polyisoprene), a member of the well-known butadiene family, in the unvulcanized state using $\mathrm{N}^{+}$ion. In this work an account of the investigations carried out in an artificial rubber, Styrene Butadiene Rubber (SBR) by low energy ion implantation will be discussed. The measurements of electrical conductivity indicates that the conductivities of SBR increases more than 9 orders of magnitude compared to pristine state and is found to increase with fluence. The evidence for conjugation, which is likely to be responsible for the enhancement of electrical conductivities, is obtained from the UV/Vis studies and from the spectra the optical band gap has been evaluated. Results of the SEM imaging shows that the $\mathrm{N}^{+}$ion implantation induces changes in surface morphology of the polyisoprene films. Besides, a comparative study has been performed with the chemically (iodine) doped SBR to check the effect of implant doping.
\end{abstract}

Index Terms-Conjugation, electrical conductivity, implantation, optical properties.

\section{INTRODUCTION}

Effects of ion implantation on a variety of polymeric and non polymeric organic thin films have been extensively studied in the past [1]-[8] and remain of considerable interest because it opens the way to develop radically new microelectronic devices [3]-[6]. A large variety of ions have been implanted in a very wide range of energies $\mathrm{E}$ $(25 \mathrm{keV}<\mathrm{E}<2 \mathrm{MeV})$ and fluences $\left(1 \times 10^{12}<\phi<1 \times\right.$ $10^{17}$ ions $/ \mathrm{cm}^{2}$ ). Major structural and chemical modifications to the parent material have been observed as an effect of ion implantation. The changes depend sensitively on mass, energy and fluence of implanted ions. Large amounts of hydrogen, $\mathrm{CO}_{2}, \mathrm{CO}$, formic acid, acetic acid and other species were detected during the process of ion implantation [2], [6]. Cross linking, conjugation and degradation of the substrate occur leading to generation of broken bonds, formation of free radicals, double bonds, and charge carriers. An increased susceptibility to oxidation for some materials have been observed [9]-[11]. However, despite the fact that the properties of ion implanted polymers were the subject of many studies, the exact structure of the implanted layer and

Manuscript received October 24, 2013; revised January 22, 2014.

Najidha S. is with the Department of Physics, B.J.M Govt:college, Chavara, Kerala, India (e-mail: najidhasb@gmail.com).

P. Predeep is with National Institute of Technology, Calicut, Kerala, India (e-mail: ppredeep@gmail.com). mechanism of the relaxation of ion beam induced defects in polymer host remain still unclear. Further, study of the phenomena that take place in the polymer films during the ion implantation is desirable for better understanding of the nature of implantation-induced conductivity which is an important prerequisite for possible applications of ion beam -modified polymers.

For higher implanted ion doses, hydrogen concentration on the sample surface decreases and the substrate becomes less or more carbonized [1]-[3].Oxidation of the ion-implanted polymers is also observed with the production of carbonyl groups as proved by infrared spectroscopy. Thus the final structure and composition of implanted polymer do not resemble the original chain structure. Further study of the properties of the ion-implanted polymer films is desirable for deeper understanding of these phenomena and also for possible applications of ion-beam-modified polymers in microelectronics.

Although modifications by ion implantation in a large number of materials have been investigated, there is little mention of the class of polymers, namely elastomers both natural and synthetic. SBR is world's most important rubber with a high market value because of its low cost and comparable mechanical properties with that of Natural Rubber. The Styrene- butadiene ratio of 25/75 roughly corresponds to a molecular ratio of approximately six butadiene units to each styrene unit [12]. Moreover they resist atmospheric deterioration than Natural Rubber and therefore can be used as a conducting material in outdoor applications. Also, raw SBR is more uniform in a variety of ways in comparison with Natural Rubber. The presence of butadiene segments with isolated double bonds opens up the possibility of chemical doping in SBR by double bond shifting reaction as observed in 1,4-polybutadienes and polyisoprenes. The purpose of the present paper is to examine in detail the modifications of the structural, electrical and optical properties of a non conjugated elastomer, SBR which is introduced during ion implantation. Here the structure of the implanted layer and its evolution in the course of the ion bombardment are studied by means of UV/Vis spectra and Scanning Electron Microscopy.

\section{EXPERIMENTAL DETAILS}

\section{A. Materials and Thin Film Preparation}

The SBR thin films, made from a solution of styrene butadiene rubber in toluene, were deposited on quartz substrate by spin coating technique. These thin films were implanted with $\mathrm{N}^{+}$ions with fluences in the range $10^{14}$ to $10^{16}$ ions $/ \mathrm{cm}^{2}$ at the Material Science Division, Indira Gandhi Centre for Atomic Research centre (IGCAR), Kalpakkam, India. The conditions used for implantations were given in 


\section{Table I.}

\section{B. Characterization}

The dc electrical conductivity measurements were performed at room temperature using a Keithly 2000 DMM. The UV/Vis spectra of the implanted films were taken using a Cary 5000 UV-Vis Spectrophotometer. The scanning electron microscopy images of the surfaces of the implanted films were taken with JEOL 5600 model Scanning Electron Microscope.

TABLE I: EXPERIMENTAL CONDIATIONS FOR ION IMPLANTATION

\begin{tabular}{ll}
\hline Chamber Pressure & $\sim 1 \times 10^{-6} \mathrm{mbar}$ \\
Ion species & $\mathrm{N}^{+}$ \\
Ion energy & $60 \mathrm{keV}$ \\
Fluence & $1 \times 10^{11}$ to $1 \times 10^{16}$ ions $/ \mathrm{cm}^{2}$ \\
Beam Current & $0.3 \mu \mathrm{A}$ \\
RF Plasma Power & $40 \mathrm{~W}$ \\
Analyzer Current & $30 \mathrm{Amps}$ \\
Suppresser Voltage & $40 \mathrm{~V}$ \\
\hline
\end{tabular}

\section{RESULT AND DISCUSSION}

A change in color of colorless starting materials is evidence for implantation-induced changes in the properties of the polymeric films. Along with the color changes an increase in the electrical conductivity is observed. The room temperature dc conductivity of implanted SBR films is found to be varied by about 9 orders of magnitude compared to virgin films. The increase in conductivity with fluence is expected to be due to an increase in concentration of double bonds and hence increase in degree of conjugation in polymer films upon ion bombardment which could be attributed [13] to the electronic energy transfer of the incident heavy ion which produces active chemical species free radicals along the polymer chain. The increases in conductivity values are consistent with the optical studies. The arrangement of the double bonds in the molecule significantly affects the chemical structure of the polymer. It is well known that the polymer absorbance is affected by the presence and degree of conjugated double bonds in the molecular chain. It has been reported [14] for UV-Visible spectra that absorption maxima are observed in conjugated systems having a higher number of double bonds.

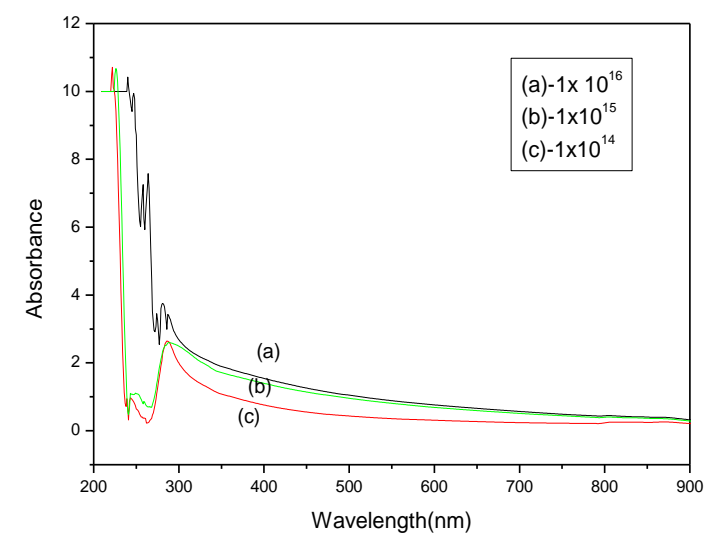

Fig. 1. UV/Vis spectra of styrene butadiene rubber at different fluences (a) at $10^{16}$ ions $/ \mathrm{cm}^{2}$, (b) at $10^{15}$ ions $/ \mathrm{cm}^{2}$ (c) at $10^{14}$ ions $/ \mathrm{cm}^{2}$.

The UV/Vis spectra of the implanted films at different fluences are presented in Fig. 1. The pristine film is colorless and shows bands at $203 \mathrm{~nm}$ and $254 \mathrm{~nm}$ which correspond to the benzene group in SBR [15], [16]. On implantation the characteristic absorption peaks are observed at about $240 \mathrm{~nm}$, $264 \mathrm{~nm}$ and $281 \mathrm{~nm}$. Thus with increasing fluence a small increase in absorption towards longer wavelength is observed.

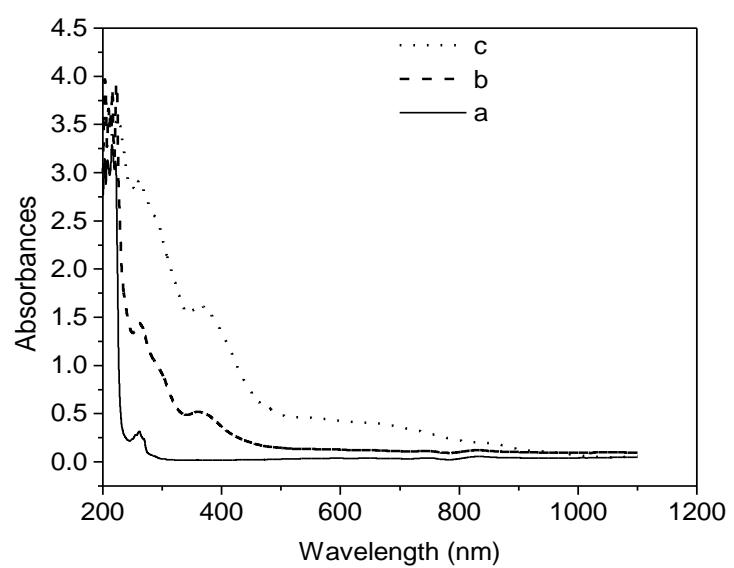

Fig. 2. The UV/Vis spectra of iodine-doped SBR films with (molar ratio 5) doped for different time intervals by solution method. a) Undoped, b) After 28 days c) After 34 days.

Fig. 2 depicts the absorption spectra of chemically (iodine) doped SBR. The UV/Vis spectra recorded for a SBR-I solution at room temperature indicate several weak bands at shorter wavelengths of $245 \mathrm{~nm}, 265 \mathrm{~nm}, 370 \mathrm{~nm}$ with a red shift is observed, which are attributable to various $(-\mathrm{CH}=\mathrm{CH}-)_{\mathrm{n}}$ sequences. Thus the doping with iodine effectively 'moves' the band to longer wavelengths as more and more conjugation is added to the benzene. A similar behaviour was observed in the case of implantation. Thus we can say that whatever the implanted ions, it can produce an effect similar to that of chemical doping along the elastomer backbone. Fig. 3 represents the absorbance of the SBR films at various $\mathrm{N}^{+}$ion fluences which showed that the absorption of the specimen implanted at higher fluences is higher.

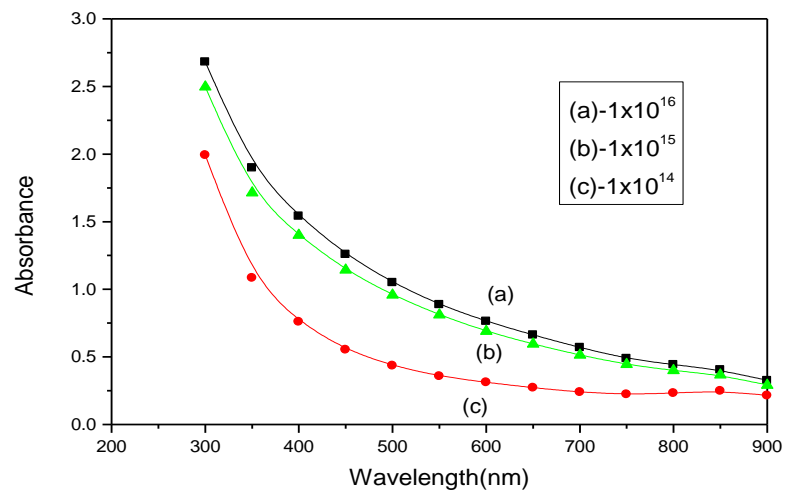

Fig. 3. Absorbance versus wavelengths of Styrene Butadiene Rubber at different fluencies (a) at $10^{16}$ ions $/ \mathrm{cm}^{2}$, b) at $10^{15}$ ions $/ \mathrm{cm}^{2}$ (c) at $10^{14}$ ions $/ \mathrm{cm}^{2}$.

The optical band gap $\left(E_{g}\right)$ can be experimentally obtained from the absorption coefficient $(\alpha)$ measurement using the general relation of the type $\alpha h v=A\left(h v-E_{g}\right)^{n}[17],[18]$ Where $\mathrm{A}$ is a constant, hu is the incident photon energy, $\mathrm{n}$ depends on the nature of the band transition; $n=1 / 2$ for direct allowed transitions; was fitted in to the experimental data. The optical band gap $\left(E_{g}\right)$ is estimated by the extrapolation of the linear portion to $(\alpha h v)^{2}=0$ in the hu versus $(\alpha h v)^{2}$ plot. 


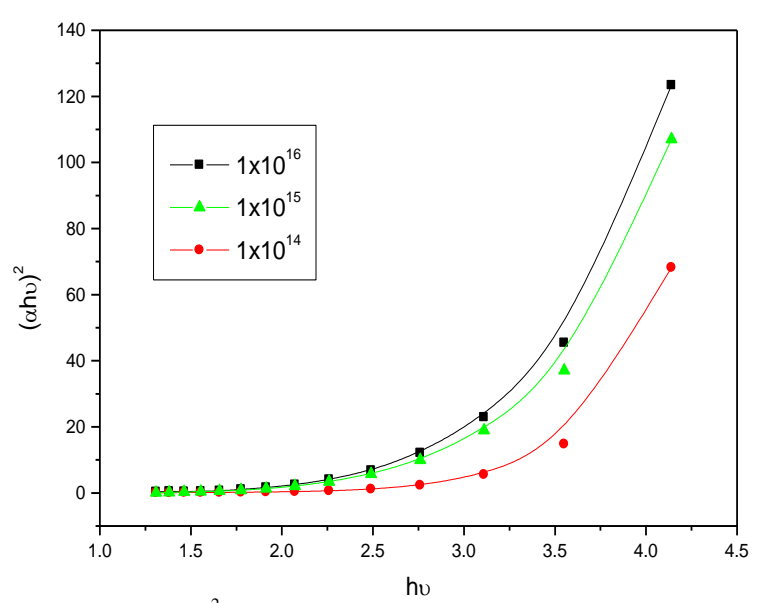

Fig. 4. $(\alpha h v)^{2}$ versus photon energy for implanted films.

It is observed that band gap decreases due to implantation (Fig. 4) which exhibits the semiconducting nature of the implanted material. Fig. 5 shows variation of optical band gap with $\mathrm{N}^{+}$implantation fluence. A total fluence of $1 \times 10^{16}$ ions $/ \mathrm{cm}^{2}$ resulted in a band gap around $2.22 \mathrm{eV}$. Thus the presence of many new peaks with increase of fluence suggests the formation of conjugation as in the case of chemically doped samples.

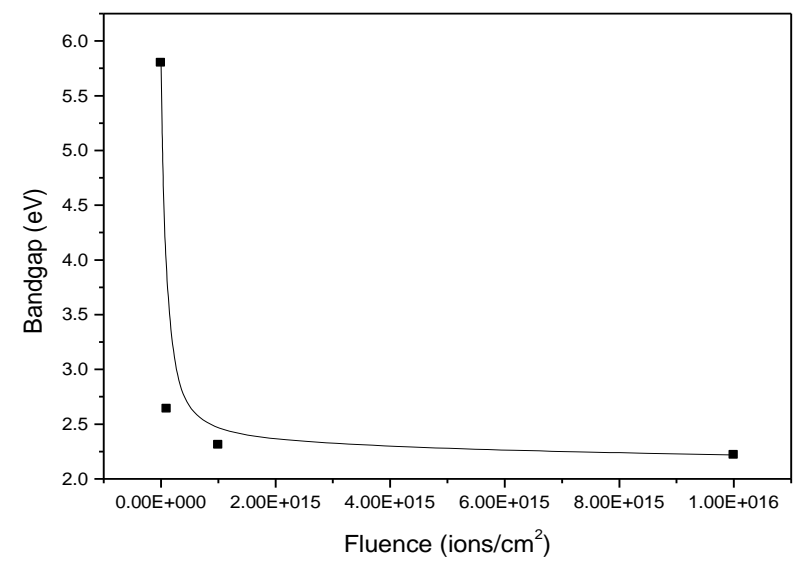

Fig. 5. Variation of $E_{g}$ with ion fluence.

Morphological changes of the SBR surface during the implantation have been investigated by SEM analysis. Fig. 6 and Fig. 7 indicate the SEM images of the implanted films at different fluences.

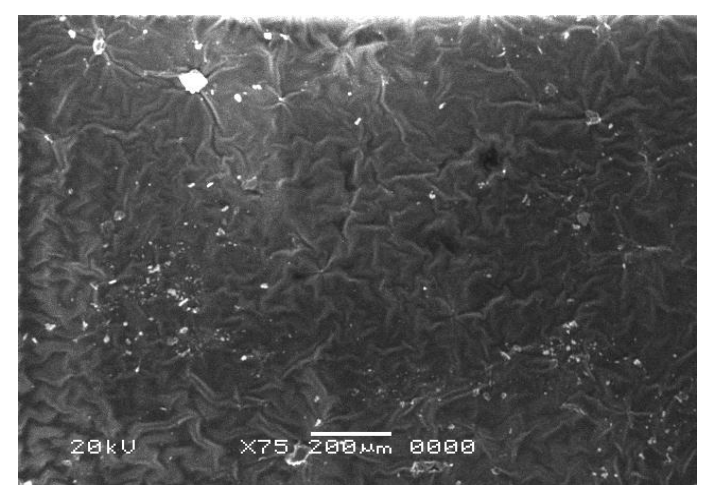

Fig. 6. SEM image of the $\mathrm{N}^{+}$ion implanted SBR film at a fluence of $1 \times 10_{14}$ ions $/ \mathrm{cm}^{2}$.

At low fluence (Fig. 6) small wrinkles are formed, but at high fluence the surface becomes smooth as in Fig. 7 (the white dots found in the figures are due to the presence of silver paste that used for SEM characterization).

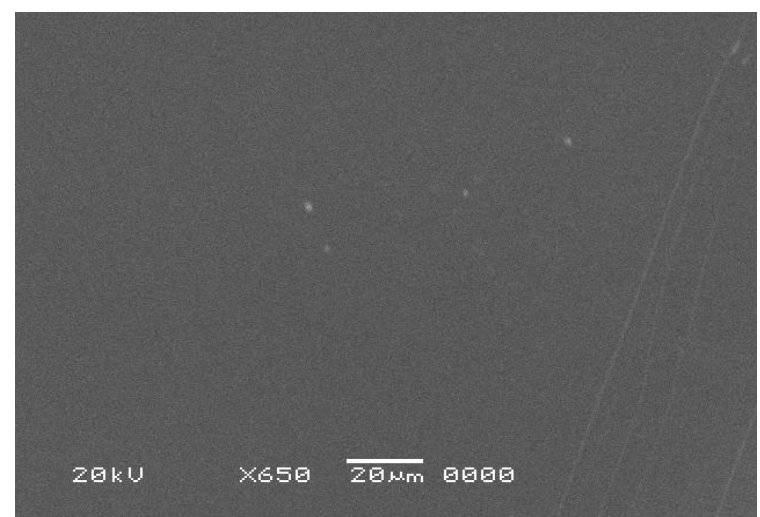

Fig. 7. SEM image of the $\mathrm{N}^{+}$ion implanted SBR film at a fluence of $1 \times 10^{16}$ ions $/ \mathrm{cm}^{2}$.

\section{CONCLUSION}

Structural modification of Styrene Butadiene Rubber during the process of ion implantation is discussed. A nine fold orders of magnitude reduction in the resistivity of these materials from their unimplanted value is observed after implanting with $60 \mathrm{keV} \mathrm{N}^{+}$ions. The process of doping in SBR by implantation has been ascertained by spectroscopical studies and it is seen that implantation leads to conjugation in the polymer as that with iodine doping. The morphological study of the surface confirms smoothening of surface on implantation.

\section{REFERENCES}

[1] V. Svorcik, V. Rybka, I. Micek, V. Popok, O. Jankovskij, V. Hnatowicz, and J. Kvitek, "Structure and properties of polymers modified by ion implantation," Eur. Polym.J., vol. 30, no. 12, pp. 1411-1415, 1994.

[2] T. Venkatesan, L. Calcagno, B. S. Elman, and G. Foti, Ion beam modification of insulators, Amsterdam: Elsevier, p. 301, 1987.

[3] K. G. Jung et al., "Modification of conducting polymers by low energy reactive ion beams and their chemical effects," Nuclear Instruments and Methods in Physics Research Section B, vol. 80, pp. 1076-1079, 1993.

[4] G. Marletta, "Chemical reactions and physical property modifications induced by $\mathrm{keV}$ ion beams in polymers," B46 Nucl.Instrum.\& Meth., p 295, 1990.

[5] U. Myler, X. L. Xu, M. R. Coleman, and P. J. Simpson, "Ion implant-induced change in polyimide films monitored by variable energy positron annihilation spectroscopy," Journal of polymer Science part B-Polymer Physics, vol. 36, no. 13, pp. 2413-2421, 1998.

[6] J. Won et al., "Surface modification of polyimide and polysulfone membranes by ion beam for gas separation," Journal of Applied Polymer Science, vol. 75, no. 12, pp. 1554-1560, 2000.

[7] S. Najidha, N. S. Saxena, R. Sreeja, and P. Predeep, "Surface modification of natural rubber by ion implantation: Evidence for implant doping," Nuclear Instruments and Methods in Physics Research B, vol. 240, 2005, pp. 850-854

[8] Q. Y. Wang, L. B. Bridwill, R. E. Giedd, and M. J. Marphy, Nucl.Instrum.\& Meth.B, vol. 56-57, p. 660, 1991.

[9] T. Fujimura, N. Hayakawa, and I. Kuriyama, J.Appl.Polym.Sci., vol. 27, p. 4093, 1982.

[10] K. Arakawa, T. Seguchi, Y. Watanabe, and N. Hayakawa, J.Polym. Sci.Polym. Chem., vol. 20, p. 2681, 1982.

[11] E. A. Hegazy, T. Sequchi, and S. Machi, J.Appl.Polym.Sci., vol. 26, 2947, 1981.

[12] D. C. Blackley, Synthetic Rubbers: Their Chemistry and Technology, p. 104.

[13] X. L. Xu, M. R. Coleman, U. Myler, and P. J. Simpson, "Photosyntheis Method for Development of Membranes Using Ion Beam Irradiation of Polyimide Thin Films," American Chemical Society, 2000, chapter 14 , pp. $205-225$. 
[14] B. Ranby and J. F. Rabek, Photodegradation, Photooxidation and Photostabilization of Polymers, London: Wiley, 1975.

[15] R. Sreeja et al., 'Electro-optic Materials from Co-polymeric Elastomer -Acrylonitrile Butadiene Rubber (NBR)-Polymer, vol. 9, no. 24, 2005.

[16] P. Predeep, R. Sreeja, P. D. Sharma, and M. Mazur, Journal of Elastomers and Plastics, vol. 18, pp. 163-170, 2005.

[17] G. P. Joshi, R. Mangal, N. S. Saxena and T. P. Sharma, Indian Journal of Pure \& Applied Physics, vol. 40, 2002, pp. 297-300.

[18] G. P. Joshi, N. S. Saxena, R. Mangal, A. Mishra, and T. P. Sharma, Bull. Mater. Sci., vol. 26, no. 4, 2003, pp. 387-389.

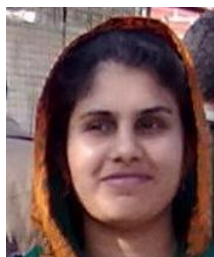

Najidha S. was born on May 28, 1980 in India. She received B.Sc (physics), Kerala University, Kerala, India, 2000; M.Sc (physics), from Kerala University, Kerala India, 2002; and Ph.D (material science-physics) from Department of Physics, University of Rajasthan, Jaipur, India.

She is presently working as assistant professor in the
Department of Physics, B. J. M. Govt: college, Chavara, Kerala, India. She had worked as an assistant professor in the Department of Physics, Govt College, Kodanchery, Calicut, India. Worked as assistant professor, Department of Physics, Farook College, Calicut, Kerala, India from November 15, 2010 to November 10, 2011. She worked as a lecturer at Fatima Mata National College, Kollam Kerala, India from June 16, 2009 to November 13,2010. She worked as an Adhoc lecturer at National Institute of Technology, Calicut, Kerala, India from 2008 to 2009. She Worked as lecturer at Sree Narayana College, Kollam, Kerala from July 16, 2007 to March 31, 2008.

She has published several papers. For example: S. Najidha, P. Predeep and Neena P. Toward "Rubbery" Nanoparticles, Journal of Applied Polymer Science, (2013) DOI: 10.1002/app.39172.

Dr. Safiya is a life member of Indian Science Congress Association (ISCA) with membership L20507. Dr. Safiya is now a senior member of IACSIT membership number 80348061. 